\title{
Influência da temperatura e da duração do molhamento foliar na severidade do míldio da cebola
}

\author{
Leandro Luiz Marcuzzo ${ }^{1}$, Maira Rodrigues Duffeck ${ }^{1}$
}

${ }^{1}$ Instituto Federal Catarinense - IFC/Campus Rio do Sul, CP 441, CEP 89.163-356, Rio do Sul, SC.

Autor para correspondência: Leandro Luiz Marcuzzo (marcuzzo@ifc-riodosul.edu.br)

Data de chegada: 22/09/2015. Aceito para publicação em: 21/07/2016.

$10.1590 / 0100-5405 / 2125$

\section{RESUMO}

Marcuzzo, L.L.; Duffeck, M.R. Influência da temperatura e da duração do molhamento foliar na severidade do míldio da cebola. Summa Phytopathologica, v.42, n.4, p.369-371, 2016.

No presente trabalho foram estudadas, em condições controladas para o desenvolvimento de um modelo climático baseado na influência da temperatura $\left(10,15,20\right.$ e $\left.25^{\circ} \mathrm{C}\right)$ e da duração do molhamento foliar $(6,12,24$ e 48 horas $)$ na severidade do míldio da cebola incitado por Peronospora destructor. A densidade relativa de lesões foi influenciada pela temperatura e pela duração do molhamento foliar $(\mathrm{P}<0,05)$. A doença foi mais severa na temperatura de $15^{\circ} \mathrm{C}$. Os dados foram submetidos à análise de regressão não linear. A função beta generalizada foi usada para ajuste dos dados de severidade e temperatura, enquanto uma função logística foi escolhida para representar o efeito do molhamento foliar na severidade do míldio da cebola. A superfície de resposta obtida pelo produto das duas funções foi expressa por $\mathrm{SE}=0,1506 *\left(\left((x-8)^{0,0614}\right)\right.$ $\left.*\left((30-x)^{0,1419}\right)\right) *(0,71642 /(1+0,56954 * \exp (-0,04460 * y)))$, onde SE, representa o valor da severidade estimada $(0,1) ; x$, a temperatura $\left({ }^{\circ} \mathrm{C}\right) \mathrm{e} y$, o molhamento foliar (horas). Este modelo climático deverá ser validado em condições de campo para aferir o seu emprego como um sistema de previsão computacional para o míldio da cebola

Palavras-chave: Allium cepa, Peronospora destructor, epidemiologia, previsão de doenças

\section{ABSTRACT}

Marcuzzo, L.L.; Duffeck, M.R. Influence of temperature and leaf wetness duration on the severity of onion downy mildew. Summa Phytopathologica, v.42, n.4, p.369-371, 2016.

In the present study, onion plants were tested under controlled conditions for the development of a climate model based on the influence of temperature $\left(10,15,20\right.$ and $\left.25^{\circ} \mathrm{C}\right)$ and leaf wetness duration $(6,12,24$ and 48 hours) on the severity of onion downy mildew caused by Peronospora destructor. The relative density of lesions was influenced by temperature and leaf wetness duration $(\mathrm{P}<0.05)$. The disease was most severe at $15^{\circ} \mathrm{C}$. Data underwent nonlinear regression analysis. Beta generalized function was used to adjust the data related to severity and temperature, while a logistic function was chosen to represent the effect of leaf wetness on the severity of onion downy mildew. The response surface obtained by the product of the two functions was expressed as $\mathrm{SE}=0.1506 *\left(\left((x-8)^{0.0614}\right)\right.$ $\left.*\left((30-x)^{0.1419}\right)\right) *(0.71642 /(1+0.56954 * \exp (-0.04460 * y)))$, where SE represents the value of the estimated severity $(0.1)$; $\mathrm{x}$, the temperature $\left({ }^{\circ} \mathrm{C}\right)$; and $y$, the leaf wetness (in hours). This climate model should be validated under field conditions to benchmark its use as a computational system for the prediction of onion downy mildew.

Keywords: Allium cepa, Peronospora destructor, epidemiology, plant disease forecast

O míldio da cebola, incitado por Peronospora destructor (Berk.) Casp. é uma importante doença na cultura e esta amplamente disseminada em regiões de clima temperado, onde são frequentes os períodos de temperaturas amenas, alta umidade e baixa luminosidade (9).

Os primeiros sintomas podem ser observados em qualquer estádio de desenvolvimento da cultura, tanto em folhas como em hastes florais aparentemente sadias, através da formação de eflorescência acinzentada constituída por esporângios e esporangióforos do patógeno (3). Com a evolução da doença, ocorre descoloração do tecido afetado, o qual adquire tonalidades de verde mais clara do que as regiões sadias das folhas. Ao aumentarem de tamanho, as manchas se alongam no sentido das nervuras e, em seguida, tornam-se necróticas (9).

O estabelecimento de uma doença depende da interação entre ambiente, patógeno e hospedeiro. Com relação ao ambiente, a temperatura e o molhamento foliar são fundamentais para o processo epidemiológico. Atualmente existem modelos matemáticos que foram desenvolvidos para predizer quais as melhores condições para a ocorrência de doenças (2). Tais modelos têm sido usados em alguns patossitemas como ferrugem da soja, míldio da videira, mancha foliar de glomerella em maçã e giberela em trigo (6). Os modelos de previsão de doenças de plantas são representações simplificadas da realidade e prevêem quais as condições mais favoráveis para o início ou o desenvolvimento futuro de uma doença, alertando para o momento de controle preventivo (1).

O objetivo deste trabalho foi elaborar um modelo climático através da relação entre diferentes valores de temperatura e da duração do molhamento foliar com a severidade do míldio da cebola.

O trabalho foi realizado no Instituto Federal Catarinense - IFC/ Campus Rio do Sul, SC. Mudas de cebola da cultivar Empasc 352 - Bola Precoce cultivadas em canteiros com 60 dias de idade apresentando três folhas expandidas foram transplantadas para copos de $300 \mathrm{~mL}$ contendo substrato comercial. As folhas foram limpas com um chumaço de algodão para retirada de cerosidade e cada copo foi coberto com um saco transparente que estava internamente umedecido com água esterilizada e fixado a base do copo para formação de uma câmara úmida, as quais 


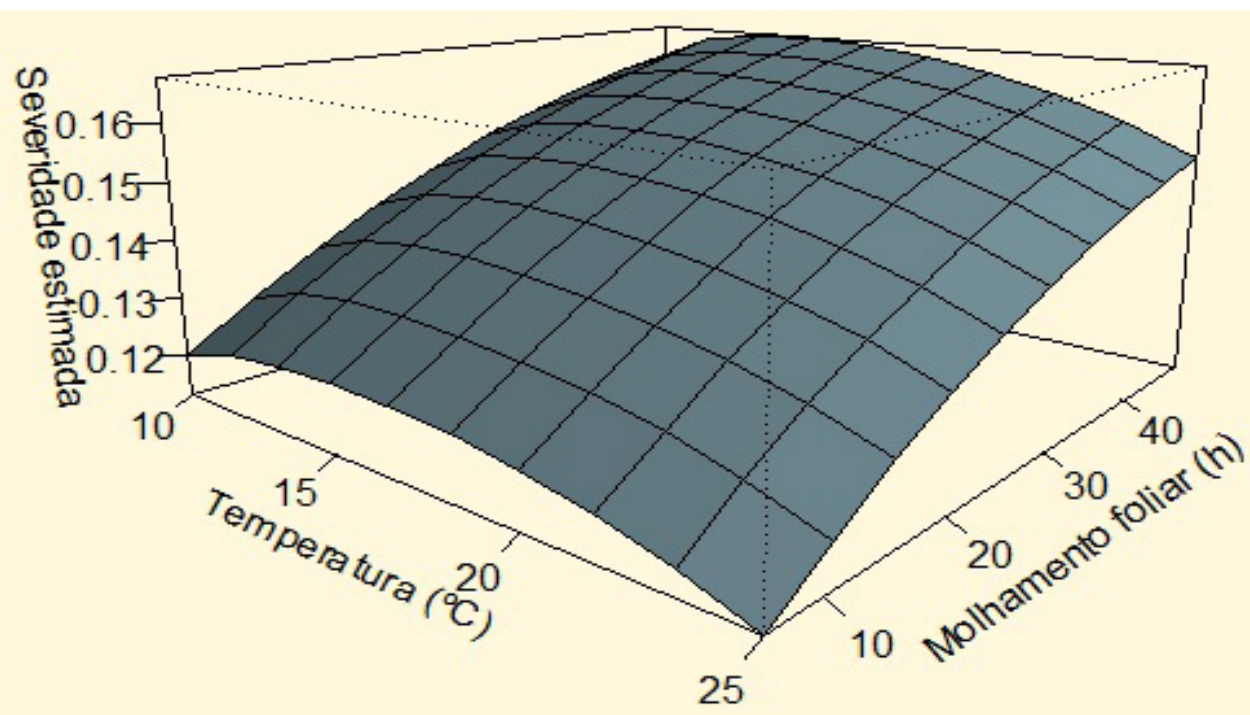

Figura 1. Severidade estimada do míldio (Peronospora destructor) da cebola cultivar Empasc 352 - Bola Precoce pela interação da temperatura e molhamento foliar representada pela função formula $\mathrm{SE}=0,1506 *\left(\left((x-8)^{0,0614}\right) *\left((30-x)^{0,1419}\right)\right) *(0,71642 /(1+0,56954 * \exp (-0,04460 * y)))$, onde: $\mathrm{SE}=$ severidade estimada $(0,1) ; x=$ temperatura $\left({ }^{\circ} \mathrm{C}\right) ; y=$ molhamento foliar $(\mathrm{h})$.

permaneceram por 24 horas. Após esse período foram inoculadas com uma suspensão de $1 \times 10^{4}$ esporos $/ \mathrm{mL}$ esporângios de $P$. destructor coletadas de plantas infectadas a campo pelo método de pulverização até o ponto de escorrimento com auxílio de um atomizador manual.

Os copos foram transferidos para estufa do tipo B.O.D ajustadas para $10,15,20$ e $25^{\circ} \mathrm{C}$ com fotoperíodo de 12 horas luz e mantidas 6 , 12,24 e 48 horas de molhamento contínuo. Ao final de cada período de molhamento, as plantas foram retiradas e secas com o auxílio de ar forçado aquecido e transferidas para sala com temperatura ambiente. A severidade da doença foi avaliada em três folhas de cada repetição através da porcentagem da área com sintoma no décimo quinto dia após a inoculação.

O delineamento inteiramente casualizado com cinco repetições foi utilizado para cada combinação de temperatura e molhamento. Cada repetição foi constituída de uma planta e a média dos valores de severidade das três folhas inoculadas foi usada para determinar a relação com a duração do molhamento foliar e temperatura.

A superfície de resposta resultou do produto de duas funções. A função beta-generalizada, expressa pela equação: $y=b 1 *(T-b 2)$ $\left.{ }^{b 4 *}(\mathrm{~b} 3-\mathrm{T})^{\mathrm{b} 5}\right)$ foi usada para determinar a resposta da severidade para as diferentes temperaturas, onde b2 é o parâmetro estimador da temperatura mínima; b3 é o parâmetro estimador da temperatura máxima; b1, b4 e b5 são parâmetros da equação; T é a variável independente, nesse caso a temperatura; e y, a severidade estimada. A função beta-generalizada, usada para modelar o efeito da temperatura na severidade, expressa o limite entre a temperatura máxima e mínima proposto pela introdução dos parâmetros no modelo e demonstra que o aumento da temperatura atua diretamente no desenvolvimento da doença até um determinado limite e logo após ocorre uma diminuição acentuada (4).

A função logística, expressa pela equação: $\mathrm{y}=\mathrm{ymax} /(1+\exp (-\ln (\mathrm{yo} /$ (ymax-yo)-r*x) foi usada para relacionar severidade com duração do molhamento foliar, em que y é a severidade estimada; ymax (máximo da severidade estimada); $\ln ($ yo/(ymax-yo) refere-se a função de proporção da doença na primeira observação; $r$ corresponde a taxa e $x$, o tempo de molhamento foliar. Essa função representa os efeitos de molhamento foliar sobre a severidade, pois à medida que aumenta o número de horas de molhamento foliar, ocorre acréscimo na severidade da doença, desde que ocorram condições favoráveis de temperatura (8).

A fórmula formula $\mathrm{SE}=0,1506 *\left(\left((x-8)^{0,0614}\right) *\left((30-x)^{0,1419}\right)\right) *$ $(0,71642 /(1+0,56954 * \exp (-0,04460 * y)))$, onde, $\mathrm{SE}=$ representa o valor da severidade estimada $(0,1) ; x$, a temperatura $\left({ }^{\circ} \mathrm{C}\right)$ e o $y$, o período de horas do molhamento foliar, foi estabelecida como modelo matemático adequado para representar a superfície de resposta (igura 1).

Notou-se um acréscimo gradativo da severidade da doença à medida que a temperatura aumentou de 10 para $15^{\circ} \mathrm{C}$, para um período contínuo de molhamento foliar. Tal efeito também foi constatado por Hildebrand $\&$ Sutton (5) que a produção de lesões teve um ótimo entre 10 e $15^{\circ} \mathrm{C}$ e baixo para $26^{\circ} \mathrm{C}$. Por outro lado, quando a temperatura passou de 20 para $25^{\circ} \mathrm{C}$ houve um decréscimo da severidade, coincidindo com os resultados obtidos por Sutton \& Hildebrand (7). Ambas as referências descritas acima não descrevem um modelo matemático para explicar o efeito. Nesse trabalho o intervalo entre 10 e $15^{\circ} \mathrm{C}$ ocorreu um acréscimo acentuado de severidade quando o período de molhamento foliar ultrapassou 10 horas. No entanto, a $25{ }^{\circ} \mathrm{C}$ houve aparecimento de sintomas mesmo após 40 horas de molhamento foliar.

As informações obtidas na interação entre temperatura e molhamento foliar permitem um maior conhecimento da epidemiologia da doença, podendo ser utilizadas para compor um modelo climático para um sistema de previsão computadorizado a ser utilizado para o míldio da cebola.

\section{REFERÊNCIAS}

1. Barreto, M.; Vale, F.X.R; Paul, P.A.; Scaloppi, E.A.G.; Andrade, D. F. A. Sistemas de previsão e estação de aviso. In: Vale, F.X.R.; Jesus Junior, W.C.; Zambolim, L. Epidemiologia aplicada ao manejo de doenças de plantas. Belo Horizonte: Perffil, 2004. p.243-266.

2. Bergamim Filho, A.; Amorim, L. Doenças de plantas tropicais: epidemiologia e controle econômico. São Paulo:Ceres, 1996. 299p.

3. Domingues, R. J.; Töfoli, J. G. Míldio da cebola: importância, identificação e métodos de controle. Biológico, São Paulo, v.71, n.1, p.29-31, 2009.

4. Hau, B. Analytic modes of plant disease in a changing environmental. Annual Review of Phytopathology, Palo Alto, v.28, n.1, p.221-245, 1990. 
5. Hildebrand, P. D.; Sutton, J. C. Relationships of temperature, moisture, and inoculums density to the infection cycle of Peronospora destructor. Canadian Journal Plant Pathology, Ottawa, v.6, n.2 p.127-134, 1984.

6. Reis, E.M. Previsão de doenças de plantas. Passo Fundo:UPF, 2004. 316p.

7. Sutton, J. C.; Hildebrand, P. D. Environmental water in relation to Peronospora destructor related pathogens. Canadian Journal Plant Pathology, Ottawa, v.6, p.323-330, 1985.
8. Vale, F.X.R.; Zambolim, L. Influência da temperatura e da umidade nas epidemias de doenças de planta. Revisão Anual de Patologia de Plantas, Passo Fundo, v.4, p.149-207, 1996.

9. Wordell Filho, J.A.; Boff, P. Queima acizentada. In: Wordell Filho, J. A.; Rowe, E.; Gonçalves, P.A.; Debarba, J.F.; Boff, P.; Thomazelli, L.F Manejo Fitossanitário na cultura da cebola. Florianópolis: EPAGRI, p.19-30, 2006. 